\title{
Necesidad de mejora en la composición tecnológica y diversificación geográfica de las exportaciones de manufacturas españolas: el caso de la ASEAN*
}

\author{
Amadeo Navarro Zapata \\ Universidad Rey Juan Carlos
}

\section{Resumen}

El insuficiente contenido tecnológico y la escasa diversificación geográfica de las manufacturas exportadas, son dos de las características del patrón de especialización de las exportaciones españolas que los distintos gobiernos han intentado corregir en los últimos años, diseñando diversos mecanismos recogidos en las diferentes estrategias de internacionalización, y cuyo fin último es la mejora en la eficiencia del sector exterior español de manufacturas. El presente trabajo, a través del análisis comparativo de las exportaciones de manufacturas españolas, de los principales países exportadores de la UE y del resto del mundo a la ASEAN, trata de determinar posibles potencialidades para las empresas manufactureras españolas en sus procesos de internacionalización en la ASEAN, con especial énfasis en las manufacturas con mayor intensidad tecnológica.

Palabras clave: exportaciones de manufacturas, intensidad tecnológica, competitividad, ASEAN.

Clasificación JEL: F14, L60, O14, O50.

\begin{abstract}
The inadequate level of technological sophistication and geographical diversification in manufactured goods exports, are two key characteristics of the Spanish export pattern. Therefore, the government has sought to amend them by implementing several schemes, outlined in many strategies aiming to improve the efficiency and competitiveness of the Spanish manufacturing sector. In this paper we conduct a comparative analysis between the Spanish manufacturing exports, the EU's largest manufacturing exporters, and ASEAN's top trading partners, in order to identify new markets and business opportunities for Spanish companies in ASEAN, mainly focused on medium- and high-skill and technology-intensive manufactures.
\end{abstract}

Keywords: manufactured good exports, technology intensity, competitiveness, ASEAN.

JEL classification: F14, L60, O14, O50.

* El autor agradece la ayuda y las sugerencias recibidas de María Arrazola Vacas, José de Hevia Payá y del evaluador anónimo. 


\section{Introducción}

La Asociación de Naciones del Sudeste Asiático ${ }^{1}$ (ASEAN), ha suscitado en la últimas décadas un especial interés debido a las múltiples transformaciones socioeconómicas que están experimentando los distintos países que la componen. Aunque el grado de desarrollo socioeconómico y la velocidad de implementación de las reformas necesarias para estimular el crecimiento económico es diferente entre los países que conforman la ASEAN, en términos generales es una de las regiones del mundo con mejores perspectivas futuras de incremento de los flujos de inversión extranjera, de crecimiento económico, y de aumento la demanda interna. La ASEAN, con una población de más de 600 millones y con unas previsiones de crecimiento del PIB del 5,1 por 100 de media en el periodo 2017-2020 (OCDE, 2017), es asimismo un importante actor del comercio internacional, importando en promedio el 7 por 100 de las importaciones mundiales de manufacturas y casi el 8 por 100 de las importaciones mundiales de manufacturas con alto contenido tecnológico ${ }^{2}$. Por tanto, la ASEAN se constituye como un mercado objetivo destacado para cualquier economía y, por supuesto, para las manufacturas españolas. La cuestión es conocer si efectivamente España está explotando, en esa región y en comparación a otros países, el potencial exportador de sus manufacturas en general, y de las de alto contenido tecnológico en particular. En este contexto, el objetivo último de este trabajo es determinar la evolución de las exportaciones de manufacturas de España a la ASEAN según su intensidad tecnológica, realizando una comparativa con la evolución de algunos de sus principales competidores, y obtener información relevante que sirva en la toma de decisiones tanto a las empresas que desean exportar sus productos a la ASEAN, como a las instituciones que participan en el diseño y ejecución de la política industrial y comercial en España.

El sector de las manufacturas abarca en líneas generales aquellas actividades industriales que a través de métodos físicos, químicos o mecánicos logran transformar materias primas, materiales y componentes diversos en productos de consumo final e industriales (Naciones Unidas, 2008). Nos vamos a centrar en el análisis de las manufacturas con alto grado de incorporación de tecnología por su relevancia en términos de estímulo al crecimiento económico. Los sectores de manufacturas que incorporan una mayor intensidad tecnológica en su producción representan una contribución importante al crecimiento de la productividad total de los factores ${ }^{3} \mathrm{y}$, por tanto, una mayor aportación al valor añadido de la economía, con importantes efectos de arrastre y eslabonamiento, y notables implicaciones en la marca país. El

${ }^{1}$ La ASEAN es un una organización supranacional fundada en 1967, compuesta por Brunei, Camboya, Indonesia, Laos, Malasia, Myanmar, Filipinas, Singapur, Tailandia y Vietnam. Entre sus principales objetivos podemos citar: acelerar el crecimiento económico de los países socios y promover la paz y la estabilidad regional.

2 Porcentajes elaborados por el autor con datos de la base de datos UNCTADstat de la Conferencia de las Naciones Unidas sobre Comercio y Desarrollo (UNCTAD).

${ }^{3}$ Entendido como la contribución al crecimiento del producto o output que no es atribuible directamente a un incremento de los inputs directos como son el trabajo, capital, recursos naturales, etc. 
presente trabajo se centra en el análisis en términos absolutos y relativos de la intensidad tecnológica de las manufacturas españolas exportadas a la ASEAN, haciendo especial énfasis en el análisis de las manufacturas exportadas con alta intensidad tecnológica, y utilizando principalmente como fuente la base de datos UNCTADstat de la Conferencia de las Naciones Unidas sobre Comercio y Desarrollo (UNCTAD) $)^{4}$. Se realiza una comparativa entre la intensidad tecnológica de las manufacturas exportadas por España, la intensidad de los nueve países de la Unión Europea $^{5}$ (UE) que exportaron en promedio un mayor valor de manufacturas durante el periodo de estudio: Alemania, Francia, Italia, Países Bajos, Reino Unido, Bélgica, Polonia, Austria y Suecia, y se amplía esta comparativa a la intensidad tecnológica de las manufacturas exportadas por algunos de los principales socios comerciales de la ASEAN, como son: Estados Unidos (EEUU), China, Taiwán, Hong Kong, Japón, Corea del Sur, Canadá y Australia. El periodo temporal del estudio está comprendido entre los años 2005 y 2015, periodo que nos permite determinar cómo ha influido la reciente crisis económica mundial sobre las variables del estudio. Asimismo, se realiza un estudio de la complementariedad, la concentración, y las ventajas comparativas reveladas de las manufacturas españolas exportadas a la ASEAN, utilizando para ello índices generalmente aceptados.

\section{Marco teórico}

Según la Teoría Neoclásica del Comercio Internacional, una de las causas por la que un país exporta sus manufacturas es la presencia de ventajas comparativas asociadas generalmente a ganancias de competitividad. Es por esto que las empresas manufactureras que destinan una importante parte de su producción a la venta en el exterior, y que desarrollan su actividad en economías abiertas y sin grandes barreras al comercio, en gran medida dedican considerables esfuerzos para mejorar su competitividad. Las Nuevas Teorías del Comercio Internacional ${ }^{6}$ (Yoffie y Hazard, 1989), por otro lado, hacen hincapié en aspectos como los rendimientos a escala o la diferenciación del producto, y aplicado a nuestro estudio, y especialmente aplicado a países desarrollados, implica que las ganancias de competitividad deberían de conseguirse no tanto por la vía de los precios, como por la vía de la innovación en productos y procesos (Helper et al., 2012), que otorga ventajas competitivas a través de la diferenciación del producto, y por tanto un cierto grado de domino de mercado.

\footnotetext{
4 Fecha de recopilación de datos: febrero del año 2017.

5 En el artículo, el acrónimo UE hace referencia a los 28 países que componen actualmente la Unión Europea.

${ }^{6}$ Componen las Nuevas Teorías del Comercio Internacional una serie de teorías y modelos que eliminan ciertos supuestos básicos de los modelos neoclásicos, como son la homogeneidad del producto, la competencia perfecta, los rendimientos constantes a escala o la presencia de información perfecta, sustituyéndolos por la competencia imperfecta, la diferenciación del producto, los rendimientos crecientes a escala y la información imperfecta. Uno de los representantes más importantes de esta nueva corriente de pensamiento es el nobel de economía Paul Krugman.
} 
Un ejemplo de materialización de la innovación es la producción de manufacturas con un alto contenido tecnológico, que contribuye a alcanzar unas tasas de crecimiento económico sostenidas en el tiempo, a la creación de empleo de calidad, y a la transformación y cambio estructural de las sociedades y economías tanto desarrolladas como en vías de desarrollo. Es un hecho estilizado que una de las herramientas para mejorar la intensidad tecnológica de las manufacturas exportadas es una mayor inversión y gasto en I+D+i (Aw et al., 2011).

Dentro de estas nuevas Teorías del Comercio Internacional podemos incluir aquellas que han introducido en el análisis nuevos elementos fundamentados en la cada vez mayor globalización de las actividades manufactureras. Grossman y Rossi-Hansberg (2006) enfatizan en la importancia de reubicar tareas (offshoring) a la hora de explicar el fenómeno de las cadenas de valor globales (CVGs), y del comercio intraindustrial. Según Grossman y Helpman (2003), estas CVGs juegan un papel importante en la transferencia de conocimiento y ganancia de competitividad entre los eslabones de dichas cadenas.

\section{Clasificación de las manufacturas atendiendo a su intensidad tecnológica}

La clasificación que se utiliza en este artículo es la establecida por la UNCTAD en su Informe sobre Comercio y Desarrollo del año 20027. Esta clasificación utiliza el sistema de codificación determinado en la Revisión 3 de la «Standard International Trade Classification» (SITC Rev.3) ${ }^{8}$, supervisada por Naciones Unidas, y cuya finalidad principal es facilitar el análisis económico y la comparación a nivel internacional de los datos del comercio internacional. Esta clasificación es idónea para los fines de este estudio, debido a que tiene en cuenta la combinación de habilidades, tecnología, capital y escala a la hora de establecer la categorización (Klotz et al., 2016) $)^{9}$, incluyendo por tanto las habilidades o skills del capital humano. Basándose en medidas como la ratio entre gasto en I+D y el valor añadido, la clasificación de la UNCTAD disgrega las manufacturas según su intensidad tecnológica y habilidades, en manufacturas de alto contenido tecnológico y habilidades, medio contenido tecnológico y habilidades, bajo contenido tecnológico y habilidades, y manufacturas

\footnotetext{
${ }^{7}$ Clasificación recogida en el anexo 1 del capitulo III del «Informe sobre Comercio y Desarrollo del año 2002» de la UNCTAD.

${ }^{8} \mathrm{https}$ //unstats.un.org/unsd/cr/registry/regcst.asp?Cl=14

${ }^{9}$ Klotz, Kniahin y Jansen (KLOTZ et al., 2016) comparan cuatro de las principales clasificaciones de productos atendiendo a su intensidad tecnológica: la «Broad Economic Categories» de Naciones Unidas, la «Process Stages» de la Organización Mundial del Comercio, la «High-Technology levels» de la OCDE, y por último la «Skill and Technology Intensity» de la UNCTAD utilizada en este artículo. Los autores concluyen que todas cumplen los requisitos para poder llevar a cabo un análisis exhaustivo sobre la intensidad tecnológica que presentan los diversos productos, y establecen grandes similitudes entre las clasificaciones de la OCDE y la UNCTAD. Asimismo, los autores señalan dos importantes inconvenientes presentes en todas ellas, en primer lugar la imposibilidad de establecer rankings de productos en cada categoría, y en segundo lugar indican que las clasificaciones están basadas en características y usos finales de los bienes, dificultando la posible evaluación de transferencia de tecnología entre industrias y sectores.
} 
intensivas en trabajo y recursos naturales ${ }^{10}$. Aunque Lall (2000) establece otra clasificación distinta a la utilizada en este artículo, podemos aplicar ciertos criterios de su definición a las características que deben presentar las distintas manufacturas para ser incluidas en cada uno de los grupos descritos anteriormente, y estas características son:

- Manufacturas intensivas en trabajo y recursos naturales. En su producción los inputs más importantes son por un lado el factor trabajo, cuyo requerimiento de cualificación es muy bajo, con habilidades tecnológicas casi nulas, y por otro lado el input de recursos naturales. Las ganancias competitivas vienen determinadas en líneas generales por la disponibilidad de los recursos naturales a precios competitivos ${ }^{11}$.

- Manufacturas de baja intensidad tecnológica. Manufacturas que requieren para su producción de mano de obra poco cualificada y la incorporación de procesos con baja intensidad tecnológica. Las manufacturas englobadas en esta sección presentan generalmente una elasticidad ingreso de la demanda baja, con una competitividad basada en mayor medida en el precio que en la diferenciación del producto, siendo los costes laborales un elemento crucial en la determinación del precio final.

- Manufacturas de contenido tecnológico medio. Este epígrafe abarca en líneas generales manufacturas que llevan incorporadas una intensidad tecnológica e inversión en I+D+i de nivel medio, con un factor trabajo de cualificación media capaz de desarrollar habilidades que en líneas generales no son fácilmente modificables en el corto plazo. Las cadenas de producción multinacionales juegan un papel destacado en la producción de este tipo de manufacturas.

- Manufacturas con alto contenido tecnológico. En su producción se ha utilizado alta tecnología con importante contenido en $\mathrm{I}+\mathrm{D}+\mathrm{i}$, que requiere asimismo la utilización de factor trabajo cualificado, que es capaz de adaptarse a un ambiente en continuo cambio tecnológico propiciado tanto por el lado de la demanda como por el lado de la oferta, y con procesos de producción que pueden variar en el corto plazo. Al igual que en el caso de las manufacturas de medio contenido tecnológico, las cadenas de producción multinacionales son actores importantes en la fabricación de este tipo de manufacturas.

${ }^{10} \mathrm{El}$ detalle exhaustivo de las manufacturas que integran cada partida se puede consultar en el sitio web: https://unstats.un.org/unsd/cr/registry/regcst.asp?Cl=14\&Top=2\&Lg=1 .

${ }^{11}$ Esta clasificación no está exenta de critica, ya que podemos encontrar en este grupo manufacturas que no se corresponden estrictamente con esta definición, por ejemplo prendas de vestir realizadas con telas innovadoras, en cuya producción hayan intervenido componentes de alta tecnología y que suponen una importante diferenciación tecnológica del producto. 


\section{Estudio comparativo de las manufacturas exportadas a la ASEAN por España y el resto de países del estudio, con especial referencia a su intensidad tecnológica}

En la «Agenda para el Fortalecimiento del Sector Industrial en España» y en la «Estrategia de Internacionalización de la Economía Española» del Ministerio de Economía, Industria y Competitividad, se establecen entre otros objetivos la necesidad de mejorar la diversificación geográfica de las exportaciones del sector manufacturero español, e incrementar su contenido tecnológico. A continuación se analizan algunos parámetros que permiten validar la necesidad de mejora de las exportaciones españolas de productos manufacturados a la ASEAN, y su composición tecnológica.

El Cuadro 1 ofrece por un lado el peso del sector manufacturero de cada uno de los países del estudio respecto al PIB, y por otro lado las manufacturas exportadas a la ASEAN respecto al total de manufacturas exportadas al mundo. Se pone de manifiesto que en líneas generales no hay una relación directa entre un mayor peso del sector manufacturero en relación al PIB, y el porcentaje de manufacturas exportadas a la ASEAN en relación al total de manufacturas exportadas. Asimismo, observamos que las manufacturas españolas exportadas a la ASEAN suponen el 1 por 100 del total de manufacturas españolas exportadas, 0,7 puntos porcentuales menos que la media de la UE, muy alejado del 3,9 por 100 que en promedio anual exportaron los países de la OCDE durante el periodo del estudio, y lejos de países como Francia e Italia, cuyos sectores manufactureros presentan unos porcentajes respecto al PIB semejantes a los de la economía española. Se puede determinar a tenor de los datos anteriores que las exportaciones de manufacturas españolas a la ASEAN presentan posibilidades de mejora.

El Cuadro 2 recoge, en promedio para el periodo 2005-2015, la composición relativa tecnológica de las manufacturas exportadas por los países considerados en el estudio respecto al mundo y respecto a los países de la ASEAN. A este respecto, si analizamos en primer lugar las exportaciones respecto al resto del mundo, según su componente tecnológico se observa que para España las manufacturas españolas de alto contenido tecnológico alcanzaron, en media para el periodo 2005-2015, el 26 por ciento del total, las manufacturas con contenido tecnológico medio alcanzaron el 46 por 100, mientras que las de bajo contenido tecnológico y las intensivas en trabajo y recursos naturales supusieron el 12 por 100 y el 16 por 100 , respectivamente. Se observa que España ocupó el puesto séptimo entre los países comunitarios del estudio con un mayor componente tecnológico en las manufacturas exportadas, lejos del 37 por 100 y del 39 por 100 de manufacturas de alto contenido tecnológico que en promedio exportaron los países de la UE y de la OCDE, respectivamente. Por otro lado, Países Bajos es, entre los países de la UE a estudio, el que más contenido tecnológico presenta en sus exportaciones de manufacturas, con un 56 por 100 de alto contenido tecnológico, seguido de Bélgica, Francia y Reino Unido. Alemania es, en términos absolutos, el principal país exportador de manufacturas de la UE y uno de 


\section{CUADRO 1 \\ PESO DEL SECTOR MANUFACTURERO EN LAS ECONOMÍAS DEL ESTUDIO, PROPORCIÓN DE MANUFACTURAS EXPORTADAS A LA ASEAN (2005-2015)}

\begin{tabular}{|c|c|c|}
\hline País & $\begin{array}{c}\text { Manufacturas exportadas en } \\
\text { relación al PIB } \\
(\%)\end{array}$ & $\begin{array}{c}\text { Manufacturas exportadas a } \\
\text { la ASEAN sobre el total de } \\
\text { manufacturas exportadas } \\
(\%)\end{array}$ \\
\hline Alemania & 31 & 1,9 \\
\hline Austria & 31 & 1,1 \\
\hline Bélgica & 63 & 0,8 \\
\hline España & 14 & 1 \\
\hline Francia & 16 & 2,8 \\
\hline Países Bajos & 40 & 1,5 \\
\hline Italia & 19 & 1,6 \\
\hline Polonia & 27 & 0,6 \\
\hline Reino Unido & 11 & 3 \\
\hline Suecia & 24 & 2,1 \\
\hline UE & 29 & 1,7 \\
\hline Estados Unidos & 6 & 5,2 \\
\hline Canadá & 13 & 1,1 \\
\hline China & 25 & 8,7 \\
\hline Hong Kong & 12 & 12,7 \\
\hline Taiwán & 52 & 14 \\
\hline Australia & 2 & 13,7 \\
\hline Japón & 12 & 13,5 \\
\hline Corea & 35 & 10,5 \\
\hline OCDE & 23 & 3,9 \\
\hline
\end{tabular}

FUENTE: Elaboración propia con datos de UNCTADstat.

los más importantes del mundo, pero si analizamos la desagregación de sus manufacturas atendiendo al componente tecnológico, podemos observar que exportó principalmente manufacturas con un componente tecnológico medio, con un promedio del 49 por 100 del total, durante el periodo de estudio. Fuera de la UE destacan Hong Kong y Taiwán, con una media del 64 por 100 y del 60 por 100, respectivamente, de manufacturas exportadas con alto contenido tecnológico. 


\section{CUADRO 2}

\section{DESAGREGACIÓN SEGÚN EL CONTENIDO TECNOLÓGICO DE LAS MANUFACTURAS EXPORTADAS AL MUNDO Y A LA ASEAN \\ (PROMEDIO 2005-2015)}

\begin{tabular}{|c|c|c|c|c|c|c|c|c|}
\hline \multirow{2}{*}{ País } & \multicolumn{4}{|c|}{ Desagregación exportaciones al mundo } & \multicolumn{4}{|c|}{ Desagregación exportaciones a la ASEAN } \\
\hline & Alto & Medio & Bajo & Trabajo & Alto & Medio & Bajo & Trabajo \\
\hline Alemania & 33 & 49 & 9 & 9 & 45 & 45 & 6 & 4 \\
\hline Austria & 25 & 45 & 16 & 14 & 42 & 40 & 10 & 8 \\
\hline Bélgica & 49 & 29 & 10 & 12 & 57 & 25 & 13 & 5 \\
\hline España & 26 & 46 & 12 & 16 & 37 & 29 & 20 & 14 \\
\hline Francia & 45 & 36 & 9 & 10 & 73 & 17 & 4 & 6 \\
\hline Países Bajos & 56 & 25 & 10 & 9 & 47 & 40 & 9 & 4 \\
\hline Italia & 23 & 41 & 13 & 23 & 27 & 48 & 11 & 14 \\
\hline Polonia & 22 & 43 & 15 & 20 & 25 & 28 & 40 & 6 \\
\hline Reino Unido & 45 & 40 & 8 & 7 & 35 & 51 & 9 & 5 \\
\hline Suecia & 31 & 42 & 12 & 15 & 32 & 45 & 10 & 12 \\
\hline Unión Europea & 37 & 40 & 11 & 12 & 48 & 38 & 8 & 6 \\
\hline Estados Unidos & 49 & 38 & 7 & 6 & 66 & 27 & 4 & 3 \\
\hline Canadá & 32 & 49 & 7 & 12 & 65 & 28 & 4 & 3 \\
\hline China & 41 & 24 & 11 & 24 & 38 & 24 & 17 & 21 \\
\hline Hong Kong & 64 & 20 & 3 & 13 & 85 & 11 & 1 & 3 \\
\hline Taiwán & 60 & 21 & 12 & 7 & 59 & 17 & 12 & 12 \\
\hline Australia & 48 & 34 & 10 & 8 & 47 & 32 & 14 & 7 \\
\hline Japón & 33 & 52 & 12 & 3 & 33 & 46 & 17 & 4 \\
\hline Corea & 45 & 32 & 18 & 5 & 46 & 22 & 22 & 10 \\
\hline OCDE & 39 & 41 & 10 & 10 & 47 & 35 & 13 & 5 \\
\hline
\end{tabular}

FUENTE: Elaboración propia a partir de datos de UNCTADstat.

En la Estrategia para la Internacionalización de la Empresa Española, anteriormente mencionada, se prevé la elaboración de planes bienales de seguimiento, actualización de los indicadores considerados y de los objetivos a alcanzar con dicha estrategia. A este respecto, a la luz de los resultados obtenidos, parece sensato establecer como objetivo a alcanzar en el próximo plan bienal, para el indicador de «incrementar el nivel tecnológico de las exportaciones españolas», conseguir que España alcance en el medio plazo los niveles que en media presentan la UE y la OCDE ${ }^{12}$.

Si se presta atención a la evolución de las manufacturas españolas exportadas según su composición tecnológica reflejada en el Gráfico 1, se observa una tendencia positiva durante el periodo del estudio, ya que en promedio el incremento anual del

\footnotetext{
12 En la Estrategia para la Internacionalización de la Empresa Española se estipula como objetivo a conseguir con horizonte 2027, que el 53 por 100 de las manufacturas contengan un componente tecnológico medio-alto, o alto, sin especificar por qué se toma ese porcentaje, ni los incrementos anuales para conseguirlo.
} 


\section{GRÁFICO 1}

\section{INTENSIDAD TECNOLÓGICA DE LAS MANUFACTURAS EXPORTADAS POR ESPAÑA (PERIODO 2005-2015. MILES DE DÓLARES)}

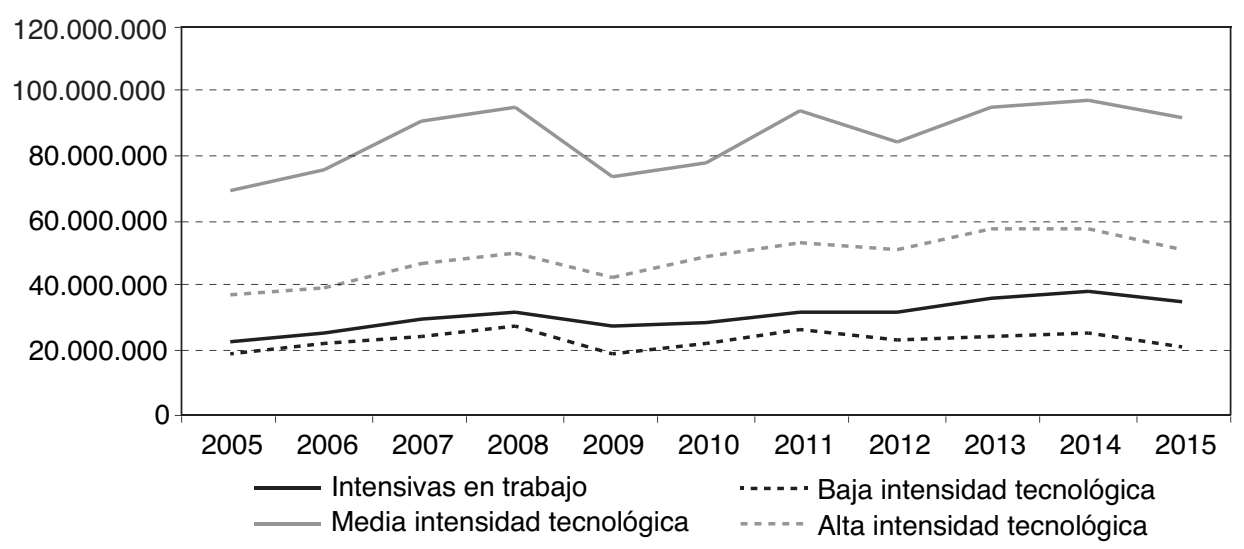

FUENTE: Elaboración propia con datos de UNCTADstat.

total de manufacturas exportadas fue del 3 por 100, igual porcentaje de incremento experimentaron las manufacturas españolas exportadas con alto y medio componente tecnológico, mientras que el incremento fue del 1 por 100 para las de bajo contenido tecnológico y del 5 por 100 para las intensivas en trabajo y recursos naturales. En el año 2008, con la llegada de la Gran Recesión, se produce un importante descenso de las exportaciones de manufacturas, pero el efecto negativo es desigual dependiendo del contenido tecnológico. En el año 2009 las exportaciones de manufacturas de baja intensidad tecnológica experimentaron una disminución del 30 por 100, mientras que las de media intensidad tecnológica disminuyeron un 22 por 100 y las manufacturas con alta intensidad tecnológica experimentaron un descenso del 14 por 100 , respecto a las cifras del año 2008. Estas cifras ponen de manifiesto una mayor resistencia de las exportaciones españolas de manufacturas de alta tecnología ante el shock que supuso la gran recesión.

En cuanto a la evolución del patrón de especialización tecnológica de las manufacturas exportadas al mundo de los principales países exportadores de manufacturas, nos encontramos que en líneas generales los patrones de Alemania, Japón y China apenas variaron, mientras que en el caso de Corea, las exportaciones de alta tecnología experimentaron un ligero descenso, pasando del 48 por 100 en el año 2005, al 43 por 100 en el año 2015. Es reseñable que Hong Kong ha experimentado en los últimos años un incremento sustancial de las exportaciones de manufacturas con alto contenido tecnológico, ya que en el año 2005 suponían el 56 por 100 del total, y en el año 2015 se situaron en el 71 por 100. Se puede establecer a tenor del análisis de los datos anteriores, que a pesar de que España necesita mejorar la proporción de las manufacturas exportadas de alta tecnología en relación al total de exportaciones de manufacturas, la evolución que las mismas han experimentado durante los años del estudio ha sido positiva. 
En el Cuadro 2 se detalla la intensidad tecnológica de las manufacturas exportadas por los países del estudio a la ASEAN. España, al igual que el resto de países de la UE a estudio, exporta a la ASEAN un porcentaje mayor de manufacturas con alto contenido tecnológico que el porcentaje que exporta al mundo, un 37 por 100 frente al 26 por 100. Francia es el país europeo del estudio que en proporción exporta a la ASEAN manufacturas con un mayor contenido tecnológico, 73 por 100, seguida de Bélgica con un 57 por 100 y Países Bajos con un 47 por 100. Fuera de la UE, podemos observar que Hong Kong, EEUU y Canadá mejoran sustancialmente la proporción de manufacturas de alto contenido exportadas a la ASEAN en relación a las exportadas al resto del mundo. En el lado opuesto están China y Taiwán, con una menor proporción.

Durante el periodo de estudio, las manufacturas de alta tecnología exportadas por España a la ASEAN supusieron un 0,8 por 100 del total de manufacturas con alto contenido tecnológico exportadas por España, un porcentaje inferior a la media de la UE, que se situó en el 2,2 por 100, y de la OCDE, que fue del 4,6 por 100. A pesar de estos datos es conveniente señalar que, como refleja el Gráfico 2, la evolución de las manufacturas de alta tecnología exportadas por España a la ASEAN fue positiva durante el periodo de estudio, y más positiva que la evolución experimentada por las manufacturas españolas exportadas al mundo reflejada en el Gráfico 1. Asimismo, durante el periodo estudiado, el incremento medio anual de las manufacturas exportadas por España a la ASEAN según su contenido tecnológico, fue del 16 por 100 para las manufacturas con alto contenido tecnológico, del 8 por 100 para las de contenido tecnológico medio, del 12 por 100 para aquellas con contenido bajo y del 18 por 100 para las intensivas en trabajo.

\section{GRÁFICO 2}

\section{INTENSIDAD TECNOLÓGICA DE LAS MANUFACTURAS ESPAÑOLAS} EXPORTADAS A LA ASEAN 2005-2015 (MILES DE DÓLARES)

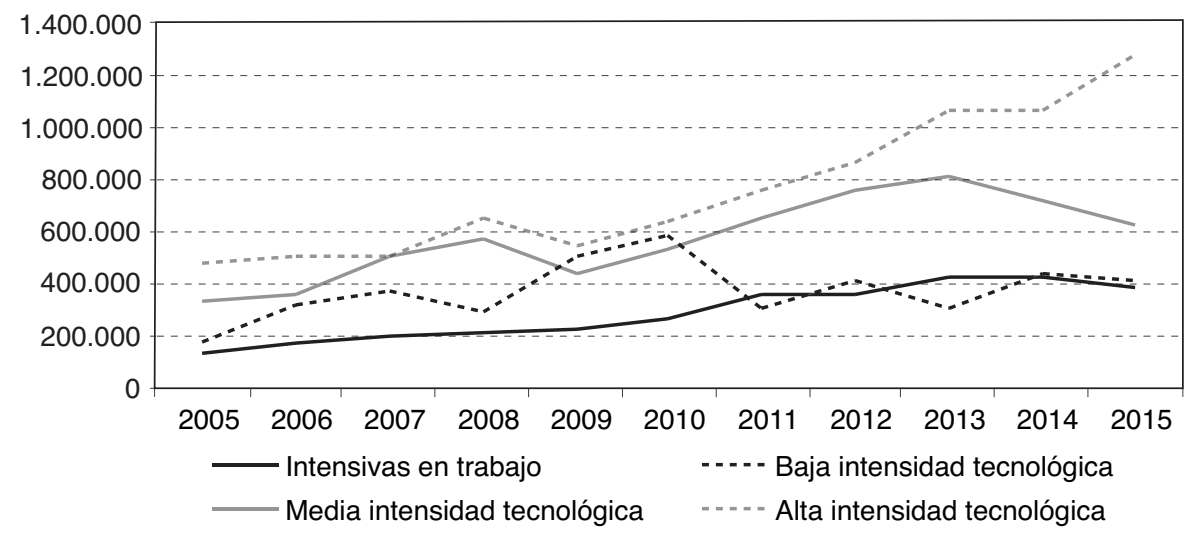

FUENTE: Elaboración propia con datos de UNCTADstat. 
La Gran Recesión supuso una disminución de las exportaciones de manufacturas de España a la ASEAN del 1,3 por 100 entre el año 2008 y el año 2009, una cifra considerablemente menor que el 25 por 100 de disminución que experimentaron los flujos de las exportaciones de manufacturas españolas al mundo.

El Gráfico 3 detalla la evolución del peso de las manufacturas de alta tecnología exportadas a la ASEAN por los cinco países con mayor PIB de la UE. Aunque es complicado evaluar en un contexto global la evolución de las exportaciones de alta tecnología, si nos centramos en el análisis de la evolución temporal observamos que aunque España presenta un peso menor que Alemania, Francia, Italia y Reino Unido, su evolución en los últimos años ha sido muy positiva, pasando de exportar a la ASEAN el 1,8 por 100 del total de las manufacturas de alta tecnología exportadas por la UE en el año 2005, a exportar el 3,6 por 100 en el año 2015. Reseñar que, en el mencionado periodo, Francia experimentó una evolución positiva, pasando del 21 por 100 al 28 por 100; Alemania no experimentó casi variación, y Reino Unido e Italia perdieron peso. Durante el periodo comprendido entre el año 2009, año en el que los cinco países registraron descensos en las manufacturas exportadas a la ASEAN debido a la Gran Recesión, y el año 2015, las exportaciones españolas de alta tecnología experimentaron un incremento del 132 por 100 , frente al 25 por 100 de Francia, 31 por 100 de Alemania, 3 por 100 de Italia y el 65 por 100 de Reino Unido.

\section{GRÁFICO 3}

\section{EVOLUCIÓN DEL PESO DE LAS MANUFACTURAS CON ALTA INTENSIDAD \\ TECNOLÓGICA EXPORTADAS A LA ASEAN POR ALEMANIA, ESPAÑA, FRANCIA, ITALIA Y REINO UNIDO, SOBRE EL TOTAL DE LA UE (PERIODO 2005-2015)}

(En \%)

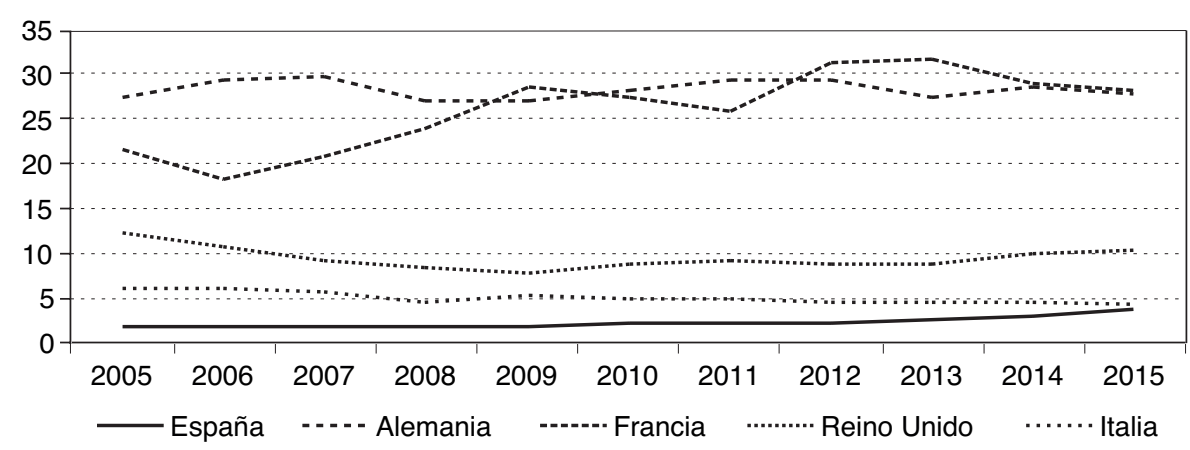

FUENTE: Elaboración propia con datos de UNCTADstat. 


\section{Importaciones de la ASEAN de manufacturas con contenido tecnológico medio y alto}

Las decisiones empresariales de exportar bienes a un nuevo mercado deben estar acompañadas por un estudio profuso de las oportunidades que ese mercado ofrece para la producción de las empresas. El estudio de las importaciones de un país refleja en parte las oportunidades que para las unidades de producción extranjeras ofrece ese mercado. Por esta razón analizamos las importaciones de manufacturas de la ASEAN, centrando el estudio en las manufacturas de medio y alto contenido tecnológico. Es conveniente señalar que las manufacturas de alto contenido importadas por la ASEAN supusieron el 58 por 100 del total, mientras que las de media intensidad tecnológica alcanzaron el 28 por 100 , lo que puede indicar una mayor propensión a importar manufacturas con un alto contenido tecnológico.

En el Cuadro 3 se presentan las diez partidas de manufacturas de media y alta intensidad tecnológica más importadas por la ASEAN durante el periodo de estudio, y el porcentaje que en promedio España exportó a la ASEAN de estas rúbricas. Observamos que a grandes rasgos, el patrón de especialización de las exportaciones de España a la ASEAN difiere de las manufacturas de alta y media intensidad tecnológica mayoritariamente demandadas por la ASEAN. La principal rúbrica de manufacturas de alta tecnología importada por la ASEAN, válvulas y tubos termiónicos, que supuso el 35 por 100 del total de las importaciones de la ASEAN de alta tecnología, ocupó el puesto vigésimo segundo entre las manufacturas más exportadas por España a la ASEAN con dicho componente tecnológico, con un porcentaje del 1 por 100. Las exportaciones de España al mundo de esta rúbrica durante el periodo de estudio alcanzaron el 0,4 por 100 del total de manufacturas de alta tecnología, ocupando el puesto cuadragésimo entre las manufacturas de esta intensidad tecnológica más exportadas por España. Por el contrario, al analizar las manufacturas de media intensidad tecnológica, observamos una mayor correspondencia entre el patrón de especialización de las exportaciones e importaciones entre España y la ASEAN, hipótesis que será ratificada con los índices de complementariedad de comercio y ventaja comparativa revelada analizados más adelante. España ocupó el puesto vigésimo cuarto entre los mayores exportadores de manufacturas de alta intensidad tecnológica a la ASEAN en términos absolutos, y fue el octavo país de la UE que más manufacturas de alta tecnología exportó al bloque asiático, a la cabeza se situaron Alemania, Francia, Italia, Bélgica, Austria y Suecia.

Japón es un buen ejemplo de la complementariedad del patrón de especialización de los flujos de comercio de manufacturas con la ASEAN, ya que el 55 por 100 de las exportaciones de manufacturas de alta tecnología niponas al bloque asiático corresponden a las cuatro rúbricas de manufacturas de alta tecnología más importadas por la ASEAN, y de ellas un 33 por 100 corresponden a la rúbrica válvulas y tubos termiónicos. Otros casos reseñables son Hong Kong, con un 54 por 100 y un 19 por 100 , respectivamente, y Alemania, con un 33 por 100 y un 18 por 100, respectivamente. 


\section{CUADRO 3}

\section{PRINCIPALES MANUFACTURAS DE MEDIO Y ALTO CONTENIDO TECNOLÓGICO IMPORTADAS POR LA ASEAN DEL RESTO DEL MUNDO Y MANUFACTURAS MÁS EXPORTADAS POR ESPAÑ̃ A LA ASEAN (PERIODO 2005-2015)}

\begin{tabular}{|c|c|c|c|c|c|c|c|}
\hline $\begin{array}{c}\text { Principales } \\
\text { manufacturas de } \\
\text { alta intensidad } \\
\text { tecnológica } \\
\text { importadas por la } \\
\text { ASEAN }\end{array}$ & $\%$ & $\begin{array}{c}\text { Principales } \\
\text { manufacturas de } \\
\text { media intensidad } \\
\text { tecnológica } \\
\text { importadas por la } \\
\text { ASEAN }\end{array}$ & $\%$ & $\begin{array}{c}\text { Principales } \\
\text { manufacturas de } \\
\text { alta intensidad } \\
\text { tecnológica } \\
\text { exportadas por } \\
\text { España a la } \\
\text { ASEAN }\end{array}$ & $\%$ & $\begin{array}{c}\text { Principales } \\
\text { manufacturas de } \\
\text { media intensidad } \\
\text { tecnológica } \\
\text { exportadas por } \\
\text { España a la } \\
\text { ASEAN }\end{array}$ & $\%$ \\
\hline \multirow[t]{2}{*}{$\begin{array}{l}\text { Válvulas y tubos } \\
\text { termiónicos }\end{array}$} & 35 & $\begin{array}{l}\text { Máquinas y apara- } \\
\text { tos eléctrico }\end{array}$ & 9 & $\begin{array}{l}\text { Aeronaves y equipo } \\
\text { conexo }\end{array}$ & 16 & $\begin{array}{l}\text { Partes, piezas y ac- } \\
\text { cesorios de los auto- } \\
\text { motores y vehículos }\end{array}$ & \\
\hline & 17 & $\begin{array}{l}\text { Equipos de teleco } \\
\text { municaciones }\end{array}$ & 11 & $\begin{array}{l}\text { Otras máquinas y } \\
\text { equipos especiales }\end{array}$ & 8 & $\begin{array}{l}\text { Pigmentos, pintu- } \\
\text { ras, barnices y ma- } \\
\text { terial conexo }\end{array}$ & 9 \\
\hline $\begin{array}{l}\text { Aparatos y maqui- } \\
\text { naria eléctricos }\end{array}$ & 7 & $\begin{array}{l}\text { Partes, piezas y ac- } \\
\text { cesorios }\end{array}$ & 7 & $\begin{array}{l}\text { Maquinaria y equi- } \\
\text { po de ingeniería ci- } \\
\text { vil y para contra- } \\
\text { tistas }\end{array}$ & 7 & Medicamentos & 8 \\
\hline $\begin{array}{l}\text { Otras máquinas, he- } \\
\text { rramientas y apara- } \\
\text { tos mecánicos }\end{array}$ & 6 & $\begin{array}{l}\text { Máquinas de proce- } \\
\text { samiento automáti- } \\
\text { co de datos }\end{array}$ & 4 & $\begin{array}{l}\text { Partes, piezas y ac- } \\
\text { cesorios de los auto- } \\
\text { motores y vehícu- } \\
\text { los }\end{array}$ & 6 & $\begin{array}{l}\text { Productos de per- } \\
\text { fumería, cosméti- } \\
\text { cos o preparados de } \\
\text { tocador }\end{array}$ & 9 \\
\hline $\begin{array}{l}\text { Equipos de calefac- } \\
\text { ción y refrigeración, } \\
\text { sus partes y piezas }\end{array}$ & 6 & $\begin{array}{l}\text { Instrumentos y apa- } \\
\text { ratos de medición, } \\
\text { verificación, análi- } \\
\text { sis y control }\end{array}$ & 3 & $\begin{array}{l}\text { Automóviles y otros } \\
\text { vehículos automo- } \\
\text { tores para el trans- } \\
\text { porte de personas }\end{array}$ & 5 & $\begin{array}{l}\text { Productos medici- } \\
\text { nales y farmacéu- } \\
\text { ticos, excepto los } \\
\text { medicamentos }\end{array}$ & 5 \\
\hline $\begin{array}{l}\text { Otras máquinas y } \\
\text { equipos especiales }\end{array}$ & 6 & $\begin{array}{l}\text { Poliacetales, otros } \\
\text { poliéteres }\end{array}$ & 2 & $\begin{array}{l}\text { Máquinas y motores } \\
\text { no eléctricos }\end{array}$ & 5 & $\begin{array}{l}\text { Poliacetales, otros } \\
\text { poliéteres }\end{array}$ & 5 \\
\hline $\begin{array}{l}\text { Grifos, llaves, vál- } \\
\text { vulas y accesorios } \\
\text { análogos para tu- } \\
\text { berías, calderas, etc }\end{array}$ & 5 & Abonos & 2 & $\begin{array}{l}\text { Motores de com- } \\
\text { bustión interna }\end{array}$ & 4 & $\begin{array}{l}\text { Polímeros de etile- } \\
\text { no en forma pri- } \\
\text { maria }\end{array}$ & 4 \\
\hline $\begin{array}{l}\text { Automóviles y otros } \\
\text { vehículos automo- } \\
\text { tores para el trans- } \\
\text { porte de personas }\end{array}$ & 4 & $\begin{array}{l}\text { Productos químicos } \\
\text { diversos }\end{array}$ & 2 & $\begin{array}{l}\text { Equipos de calefac- } \\
\text { ción y refrigeración, } \\
\text { sus partes y piezas }\end{array}$ & 4 & $\begin{array}{l}\text { Tubos, caños y man- } \\
\text { gueras de plásticos }\end{array}$ & 4 \\
\hline $\begin{array}{l}\text { Aparatos eléctricos } \\
\text { rotativos y sus par- } \\
\text { tes y piezas }\end{array}$ & 4 & $\begin{array}{l}\text { Polímeros de etile- } \\
\text { no, en formas pri- } \\
\text { marias }\end{array}$ & 2 & $\begin{array}{l}\text { Bombas, compre- } \\
\text { sores, ventiladores } \\
\text { y campanas de aire }\end{array}$ & 4 & $\begin{array}{l}\text { Equipos de teleco- } \\
\text { municaciones, sus } \\
\text { partes y piezas. }\end{array}$ & 3 \\
\hline $\begin{array}{l}\text { Equipos mecánicos } \\
\text { de manipulación y } \\
\text { sus partes y piezas }\end{array}$ & 3 & Medicamentos & 2 & $\begin{array}{l}\text { Aparatos eléctricos } \\
\text { rotativos, sus par- } \\
\text { tes y piezas }\end{array}$ & 3 & $\begin{array}{l}\text { Aceites esenciales, } \\
\text { materias aromati- } \\
\text { zantes y saporíferas }\end{array}$ & 3 \\
\hline $\begin{array}{l}\text { Bombas, compre- } \\
\text { sores, ventiladores } \\
\text { y campanas de aire }\end{array}$ & 3 & & & & & & \\
\hline
\end{tabular}

FUENTE: Elaborado propia con datos de UNCTADstat. 


\section{6. Índices de complementariedad, de concentración y de ventaja comparativa revelada.}

El análisis de los determinantes de los flujos de exportaciones de un país a un determinado mercado es muy complejo, y en la literatura científica se han analizado de forma profusa los determinantes tanto del lado de la demanda como de la oferta, tales como los costes de transportes, los costes laborales, el grado de apertura de los mercados, los flujos de inversión directa extranjera, etc. (Fugazza, 2004; Chen et al., 2016). En este artículo se analiza si la complementariedad entre los patrones de exportaciones e importaciones, la concentración por el lado de la oferta, y la presencia de ventajas comparativas, pueden influir a la hora de exportar manufacturas con alto contenido tecnológico a la ASEAN. Se trata, por tanto, de determinar en qué medida España y los demás países considerados en el estudio exportan aquellas manufacturas con alto y medio contenido tecnológico más demandadas por la ASEAN, analizar asimismo, si las exportaciones de manufacturas con intensidad tecnológica alta están muy concentradas, si esa concentración se materializa en las manufacturas más demandadas por la ASEAN, si la concentración está o no relacionada con una mayor exportación, y por último determinar si los países del estudio presentan o no ventajas comparativas en las manufacturas intensivas en tecnología más demandadas por la ASEAN. Aunque, sin duda este análisis tiene limitaciones, pensamos que puede contribuir a orientar el diseño e implementación de las estrategias de internacionalización, tanto para las empresas como para los organismos públicos y privados encargados de elaborar y ejecutar propuestas de política económica encaminadas a mejorar la presencia de las empresas manufactureras españolas en el exterior.

El estudio de los índices de complementariedad de comercio pueden ser no solo una herramienta útil en el análisis de la complementariedad entre las exportaciones e importaciones de países o grupo de países, sino que también pueden ayudar en el análisis del incremento de las exportaciones en economías que desean profundizar en su integración económica ${ }^{13}$. Aplicados a nuestro trabajo, pueden ayudar a determinar para el caso de España y demás países europeos del estudio, la existencia de posibles ganancias en el comercio de manufacturas, para el caso de una mayor integración económica y comercial entre la UE y la ASEAN, ya que del estudio de la complementariedad obtenemos el grado de compatibilidad entre las importaciones de un país y las exportaciones de su socio comercial (Organización Mundial del Comercio, 2012). En nuestro estudio utilizamos el índice de complementariedad generalmente aceptado y propuesto por Michaely (1996), acotado a las manufacturas de alto y medio contenido tecnológico, y definido como:

\footnotetext{
${ }^{13}$ En el manual elaborado por el Departamento de Comercio Internacional de la Organización Mundial del Comercio, se estipula la idoneidad en la utilización de este índice como ayuda en el estudio de la expansión de las exportaciones ante acuerdos de comercio preferenciales: http://wits.worldbank.org/WITS/docs/TradeOutcomes-UserManual.pdf
} 


$$
S e_{j} m_{k}=1-\frac{\sum_{i}\left|E_{i j}-M_{i k}\right|}{2}
$$

donde $S e_{j} m_{k}$ es el índice de complementariedad ${ }^{14}$ del exportador o grupo de exportadores $j$ con el importador o grupo de importadores $k$ en relación al grupo de productos i. $E_{i j}$ mide la proporción de las exportaciones del producto o partida $i$, sobre el total de las exportaciones al mundo del país o grupo de países $j . M_{i k}$ mide el peso del producto o partida $i$, sobre el total de importaciones del mundo del país $k^{15}$.

En el Cuadro 4 se presentan los resultados obtenidos en el cálculo del índice de complementariedad entre las importaciones de manufacturas de medio y alto contenido tecnológico de la ASEAN, y las exportaciones de estas manufacturas de España y el resto de países considerados hacia dicha área, para el periodo de estudio. Como se puede observar China es el país que presenta una mayor complementariedad con la ASEAN en el patrón de exportaciones e importaciones de manufacturas con alto contenido tecnológico, seguida de Hong Kong, Taiwán, Japón y EEUU ${ }^{16}$. Entre los países de la UE del estudio destaca Francia. España presenta unos valores del índice en línea con la media de la UE en relación a las manufacturas de alta tecnología, y una mayor complementariedad en relación a las manufacturas de intensidad tecnológica media. Exceptuando China, el resto de países del estudio tiene una mayor complementariedad con la ASEAN en el patrón de exportaciones e importaciones de manufacturas de contenido tecnológico medio, que en el patrón de manufacturas con alto contenido tecnológico.

La Comisión Europea ha concluido, aunque aún pendientes de ratificación, acuerdos de libre comercio con Singapur y Vietnam, y están en marcha negociaciones para concluir acuerdos del mismo tipo con Malasia, Tailandia, Indonesia y Myanmar. El fin último de todos estos acuerdos es alcanzar uno más amplio con la ASEAN. A este respecto, el análisis de los resultados obtenidos con el índice de complementariedad, indica que en líneas generales una profundización en la integración comercial entre la UE y la ASEAN podría ser beneficiosa para los sectores manufactureros de alta y media intensidad tecnológica de España y del resto de los países de la UE a estudio, teniendo en cuenta las limitaciones del propio concepto de complementariedad, al tratarse de dos bloques económicos con un importante peso en la economía global,

${ }^{14}$ Este índice fluctúa entre cero y uno, siendo cero el valor que indica que la complementariedad es nula entre la estructura de comercio de exportaciones del país $j$ y la estructura de importaciones del país $k$, y siendo uno el valor representativo de una complementariedad total entre las mencionadas estructuras de comercio.

$15 E_{i j}$ correspondería, por ejemplo, a la proporción del total de manufacturas de la partida de «equipos de telecomunicaciones» que España exporta a la ASEAN respecto al total que exporta al mundo. Por otra parte, $M_{i k}$ correspondería a la proporción del total de manufacturas de la partida «equipos de telecomunicaciones» que importa la ASEAN sobre el total de importaciones de la ASEAN.

16 Una de las importantes limitaciones que presenta la utilización del índice de complementariedad de Michaely radica en la necesidad de establecer el peso que las exportaciones de un país tiene sobre las importaciones del socio comercial, ya que si este peso es muy importante, puede desvirtuar el valor del índice. Para completar este análisis habría que tener en cuenta elementos relacionados con una mayor presencia de redes comerciales de las empresas del país exportador en el país importador, o con tener cierto poder de mercado, etc. 
y siempre y cuando los niveles del precio del petróleo y otros costes no sean muy elevados ${ }^{17}$.

En el Cuadro 4 se presentan también los resultados obtenidos en el cálculo de índices de concentración. Dichos índices proporcionan información acerca del nivel de concentración o diversificación de las exportaciones de un país o grupo de países, con respecto a las importaciones de otro país o grupo de países. El estudio de las ventajas y desventajas a nivel país de la diversificación de las exportaciones en un determinado mercado es complejo (Carrere et al., 2011), ya que aunque por un lado una mayor diversificación limita el riesgo para el país exportador ante un shock de demanda de un producto o partida de productos, por otro lado una concentración de las exportaciones en los productos más demandados por el país importador podría reflejar una mayor eficiencia en la asignación de recursos, es decir focalizar los recursos hacia aquellos productos en los que se presentan ventajas comparativas en su producción ${ }^{18}$. Es por esto que en este trabajo se analiza el nivel de concentración de las exportaciones de manufacturas con alta intensidad tecnológica de los países del estudio a la ASEAN, y además determinamos si esta concentración se materializa en las partidas de manufacturas con alta intensidad tecnológica más demandadas por la ASEAN. La tercera columna del Cuadro 4 nos informa del nivel de concentración de las exportaciones de manufacturas con alta intensidad tecnológica de los países del estudio a la ASEAN, y la cuarta columna nos detalla el nivel de concentración de las exportaciones en las tres manufacturas más importadas por la ASEAN ${ }^{19}$, las cuales representan por sí solas el 53 por 100 del total de las manufacturas con alto contenido tecnológico importadas por la ASEAN. El índice utilizado es el propuesto por Herfindahl (1950) y Hirschmann (HH) $(1945)^{20}$, definido como:

$$
H H_{j k}=\frac{\sqrt{\sum_{i=1}^{n}\left(\frac{x_{i j k}}{x_{j k}}\right)^{2}}-\sqrt{\frac{1}{n}}}{1-\sqrt{\frac{1}{n}}}
$$

\footnotetext{
${ }^{17}$ Para determinar ganancias derivadas de una mayor integración, habría que tener en cuenta como ya hemos indicado más elementos en el análisis, como por ejemplo que el precio final de las mercancías al disminuir o desaparecer los aranceles sea inferior a los precios de los principales competidores.

${ }^{18}$ Las teoría que ahondan en la ventaja comparativa han sido tratadas profusamente desde el inicio de la Teoría del Comercio Internacional, autores como Ricardo, Hecksher y Ohlin, fueron pioneros en establecer la relación entre la producción de un bien y la presencia de ventajas comparativas relativas en la producción del mismo.

19 Válvulas y tubos termiónicos; equipos de telecomunicaciones, sus partes y piezas; y partes, piezas y accesorios de máquinas de oficina y de proceso de datos.

${ }^{20}$ Un valor cercano a cero indica que las exportaciones están distribuidas de una forma más homogénea y que la concentración de las exportaciones en un producto o grupo de productos es menor. Al contrario sucede si el valor es uno o cercano a uno. Este índice al igual que una gran mayoría de los índices de medición de la diversificación de las exportaciones presenta problemas de simetría que serán más o menos importantes dependiendo del grado de desagregación de la clasificación empleada.
} 
donde $X_{i j k}$ son las exportaciones del país $j$ de la manufactura con alta intensidad tecnológica $i$, con destino al país o grupo de países $k . X_{j k}=\sum_{i=1}^{n} X_{i j k}$ representa el valor total de las manufacturas con alta intensidad tecnológica exportadas por el país $j$ con destino el país o grupo de países $k$. Se observa a través de los valores que toman los índices de concentración reflejados en el Cuadro 4, que los países del estudio que más manufacturas exportan a la ASEAN en términos absolutos y relativos, no presentan una concentración significativa en sus manufacturas exportadas a la ASEAN con mayor intensidad tecnológica, aunque sí se aprecia que las manufacturas con dicha intensidad tecnológica que más exportan estos países a la ASEAN son las que más demanda este bloque comercial. Se observa, asimismo, que la concentración

\section{CUADRO 4}

ÍNDICES DE COMPLEMENTARIEDAD Y CONCENTRACIÓN DE LAS MANUFACTURAS EXPORTADAS A LA ASEAN (PROMEDIO 2005-2015)

\begin{tabular}{|l|c|c|c|c|}
\hline \multicolumn{1}{|c|}{ País } & $\begin{array}{c}\text { Índice de } \\
\text { complementariedad } \\
\text { País-ASEAN } \\
\text { manufacturas con } \\
\text { intensidad } \\
\text { tecnológica alta }\end{array}$ & $\begin{array}{c}\text { Índice de } \\
\text { complementariedad } \\
\text { País-ASEAN } \\
\text { manufacturas con } \\
\text { intensidad } \\
\text { tecnológica media }\end{array}$ & $\begin{array}{c}\text { Índice HH para } \\
\text { manufacturas con } \\
\text { alta intensidad } \\
\text { tecnológica }\end{array}$ & $\begin{array}{c}\text { Índice HH para } \\
\text { manufacturas con } \\
\text { alta intensidad } \\
\text { tecnológica más } \\
\text { importadas por la } \\
\text { ASEAN }\end{array}$ \\
\hline Alemania & 0,8187 & 0,9644 & 0,1473 & 0,2327 \\
\hline Austria & 0,8154 & 0,9335 & 0,5115 & 0,2814 \\
\hline Bélgica & 0,8168 & 0,9339 & 0,1212 & 0,0528 \\
\hline España & 0,8165 & 0,9342 & 0,0805 & 0,1085 \\
\hline Francia & 0,8232 & 0,9350 & 0,4561 & 0,0218 \\
\hline Países Bajos & 0,8172 & 0,9350 & 0,0492 & 0,0460 \\
\hline Italia & 0,8168 & 0,9364 & 0,0822 & 0,0593 \\
\hline Polonia & 0,8156 & 0,9338 & 0,1475 & 0,0647 \\
\hline Reino Unido & 0,8185 & 0,9383 & 0,0906 & 0,0330 \\
\hline Suecia & 0,8176 & 0,9367 & 0,5145 & 0,5020 \\
\hline UE & 0,8160 & 0,9068 & 0,1899 & 0,1202 \\
\hline EEUU & 0,8351 & 0,9043 & 0,3168 & 0,3101 \\
\hline Canadá & 0,8169 & 0,9051 & 0,3842 & 0,0540 \\
\hline China & 0,9431 & 0,9142 & 0,1882 & 0,1658 \\
\hline Hong Kong & 0,8640 & 0,9105 & 0,3190 & 0,3190 \\
\hline Taiwán & 0,8522 & 0,9145 & 0,5967 & 0,5967 \\
\hline Australia & 0,8197 & 0,9074 & 0,1847 & 0,0795 \\
\hline Japón & 0,8426 & 0,9319 & 0,2558 & 0,2508 \\
\hline Corea & 0,8287 & 0,9146 & 0,3663 & 0,3652 \\
\hline OCDE & 0,8294 & 0,9092 & 0,2319 & 0,2262 \\
\hline
\end{tabular}

FUENTE: Elaboración propia a partir de datos de UNCTADdstat. 
que presentan las exportaciones españolas de manufacturas con alta intensidad tecnológica a la ASEAN es baja, tanto en lo referente al total de manufacturas de alto contenido tecnológico, valor recogido en la columna tres, como también en el caso de las tres manufacturas más importadas por la ASEAN, recogido en la columna cuarta, con niveles de concentración menores que la media de la UE y de la OCDE.

Como hemos visto a lo largo del estudio, y aunque el nivel de concentración de las manufacturas de alto y medio contenido tecnológico importadas por la ASEAN es relativamente alto, en líneas generales la concentración de las manufacturas con alto contenido tecnológico exportadas por los países del estudio, presenta un nivel bajo.

El índice de ventaja comparativa revelada (VCR) permite medir de forma indirecta la competitividad exterior de las exportaciones de un país, y además permite valorar el potencial de las exportaciones de una economía. Las conclusiones que pueden obtenerse por tanto del análisis del índice de VCR son diversas, entre estas se pueden citar la posibilidad de establecer el patrón de especialización de las mercancías exportadas por un país, o determinar si los recursos se están asignando de una forma eficiente hacia actividades de alto valor añadido. Utilizamos como índice de $\mathrm{VCR}^{21}$ el generalmente aceptado y propuesto por Balassa (1965), definido como:

$$
\operatorname{VCR}_{j}^{i}=\left(\frac{\left(\frac{X_{j}^{i}}{X^{i}}\right)}{\left(\frac{X_{j}}{X}\right)}\right)
$$

donde $X_{i}^{j}$ son las exportaciones del país $j$ del bien $i, X_{j}=\sum_{i} x_{i}^{j}$ son las exportaciones totales del país $j, X_{i}=\Sigma_{j} X_{i}^{j}$ son las exportaciones mundiales del producto $i$, $X=\sum_{j} \sum_{i} X_{i}^{j}$ son las exportaciones mundiales. Un valor de VCR mayor que la unidad implica que el país presenta una ventaja comparativa revelada en el producto, y si es menor que la unidad no presentaría dicha ventaja.

En el Cuadro 5 se detallan las VCR de los países del estudio correspondientes a las seis partidas de manufacturas con alta intensidad tecnológica más importadas por la ASEAN. Observamos que España, durante el periodo de estudio, presenta únicamente VCR en una de las seis partidas, poliacetales, otros poliéteres y resinas epoxídicas, con unos índices para las restantes partidas por debajo de los promediados para la UE y la OCDE.

El Cuadro 6 ofrece la evolución temporal durante el periodo muestral considerado de las VCR de todas las partidas de manufacturas españolas con alto contenido tecnológico detalladas en la SITC Rev.3, con una desagregación a tres dígitos. Se observa que en el año 2015 España presentó VCR en veintiuna partidas de manufacturas sobre un total de cincuenta y seis, con una evolución positiva en el número

${ }^{21}$ El índice de VCR de Balassa representa en buena medida la esencia de la Teoría Ricardiana del Comercio Internacional, e introduce el concepto «revelada» con el fin de establecer que a través del estudio de los patrones de comercio, se revela o determina la existencia de la ventaja comparativa. 


\section{CUADRO 5}

ÍNDICES DE VCR DE LAS MANUFACTURAS CON ALTA INTENSIDAD TECNOLÓGICA MÁS IMPORTADAS POR LA ASEAN (PROMEDIO 2005-2015)

\begin{tabular}{|l|c|c|c|c|c|c|}
\hline \multicolumn{1}{|c|}{ País } & $\begin{array}{c}\text { Válvulas } \\
\text { y tubos } \\
\text { termiónicos }\end{array}$ & $\begin{array}{c}\text { Equipos de } \\
\text { telecomuni- } \\
\text { cación }\end{array}$ & $\begin{array}{c}\text { Partes, piezas } \\
\text { y accesorios } \\
\text { para } \\
\text { máquinas } \\
\text { de oficina }\end{array}$ & $\begin{array}{c}\text { Máquinas de } \\
\text { procesamiento } \\
\text { automático de } \\
\text { datos }\end{array}$ & $\begin{array}{c}\text { Instrumentos } \\
\text { yaparatos } \\
\text { de medición, } \\
\text { verificación, } \\
\text { análisis y } \\
\text { control }\end{array}$ & $\begin{array}{c}\text { Poliacetales, } \\
\text { otros } \\
\text { poliéteres } \\
\text { y resinas } \\
\text { epoxídicas }\end{array}$ \\
\hline Alemania & 0,442 & 0,486 & 0,621 & 0,510 & 2,024 & 1,018 \\
\hline Austria & 0,395 & 0,484 & 0,312 & 0,269 & 1,173 & 0,725 \\
\hline Bélgica & 0,118 & 0,193 & 0,395 & 0,265 & 0,454 & 1,711 \\
\hline España & 0,115 & 0,169 & 0,144 & 0,112 & 0,387 & 2,172 \\
\hline Francia & 0,512 & 0,475 & 0,259 & 0,306 & 1,294 & 0,568 \\
\hline Países Bajos & 0,472 & 0,913 & 1,933 & 1,616 & 0,731 & 2,812 \\
\hline Italia & 0,170 & 0,287 & 0,155 & 0,151 & 0,784 & 1,220 \\
\hline Polonia & 0,094 & 0,579 & 0,253 & 0,663 & 0,401 & 0,780 \\
\hline Reino Unido & 0,288 & 0,885 & 0,729 & 0,575 & 1,916 & 0,497 \\
\hline Suecia & 0,182 & 1,820 & 0,234 & 0,474 & 1,304 & 0,250 \\
\hline UE & 0,334 & 0,653 & 0,636 & 0,653 & 1,219 & 1,143 \\
\hline EEUU & 1,097 & 0,865 & 1,164 & 0,964 & 2,280 & 1,258 \\
\hline Canadá & 0,159 & 0,433 & 0,209 & 0,209 & 0,829 & 0,435 \\
\hline China & 1,121 & 2,834 & 1,875 & 4,062 & 0,517 & 0,655 \\
\hline Hong Kong & 4,450 & 4,479 & 2,240 & 1,614 & 0,961 & 1,305 \\
\hline Taiwán & 6,567 & 1,348 & 2,177 & 0,638 & 0,643 & 3,958 \\
\hline Australia & 0,033 & 0,130 & 0,231 & 0,116 & 0,400 & 0,069 \\
\hline Japón & 1,757 & 0,638 & 1,605 & 0,268 & 2,151 & 1,066 \\
\hline Corea & 2,679 & 2,631 & 1,198 & 0,704 & 0,521 & 2,750 \\
\hline OCDE & 0,634 & 0,768 & 0,746 & 0,653 & 1,366 & 1,100 \\
\hline
\end{tabular}

FUENTE: Elaborado propia a partir de datos de UNCTADstat.

total de partidas con presencia de VCR, ya que en el año 2005 fueron diecinueve el número de partidas que presentaban dicha ventaja. Las partidas de manufacturas exportadas por España con alto contenido tecnológico que destacan por presentar una mayor VCR son: la partida de extractos tintóreos y curtientes, que ocupa el puesto trigésimo primero entre las manufacturas españolas más exportadas a la ASEAN; la partida de pigmentos, pinturas y barnices, que ocupa el segundo puesto; la partida de productos de perfumería y cosméticos o preparados de tocador (excepto jabones), que ocupa el cuarto puesto; y la partida de insecticidas, raticidas, fungicidas, herbicidas, productos antigerminantes y reguladores del crecimiento de las plantas, que ocupa el puesto vigésimo cuarto. 


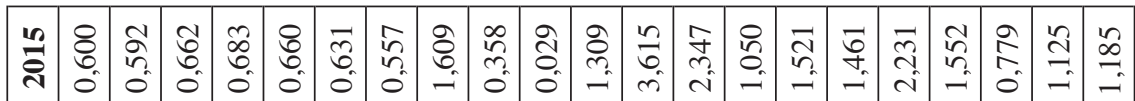

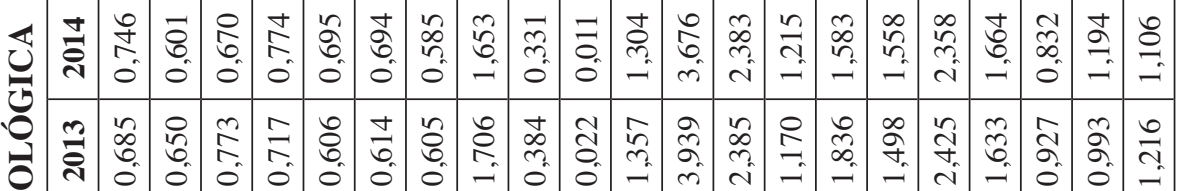

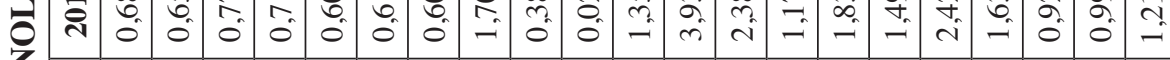

己

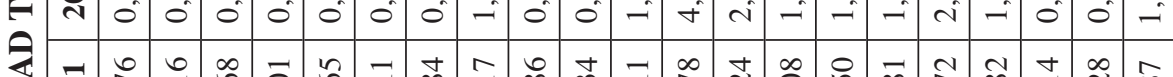

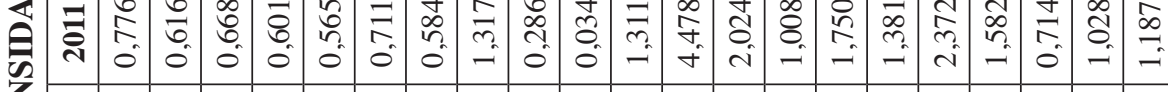
司

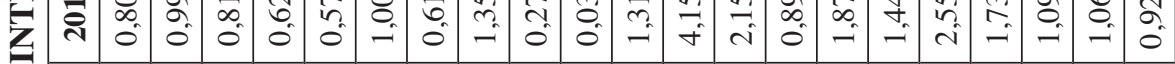

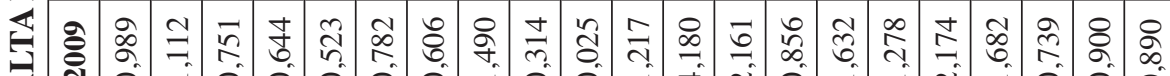

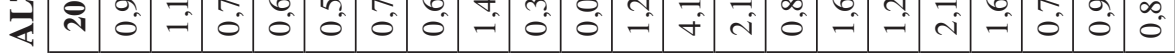

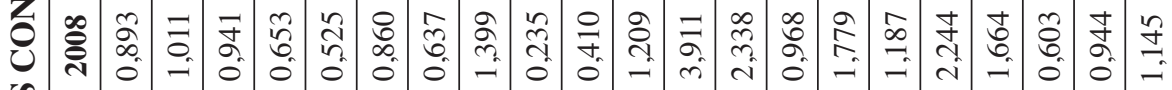
官

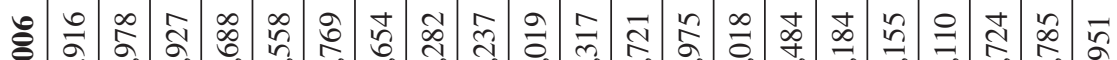

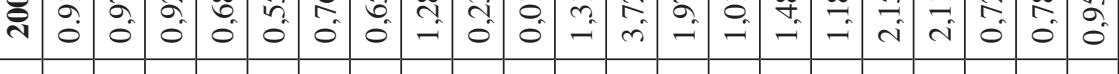

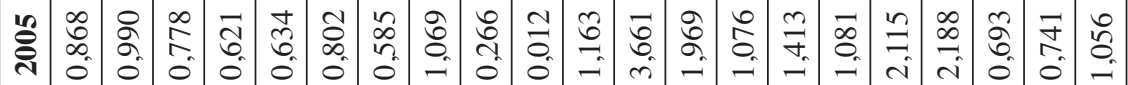
1 


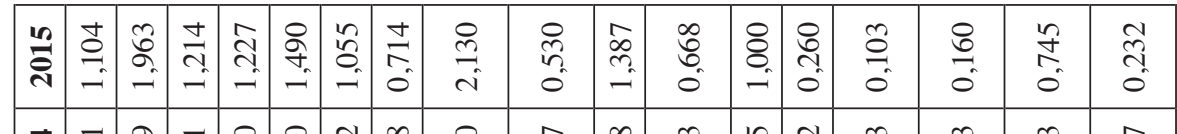

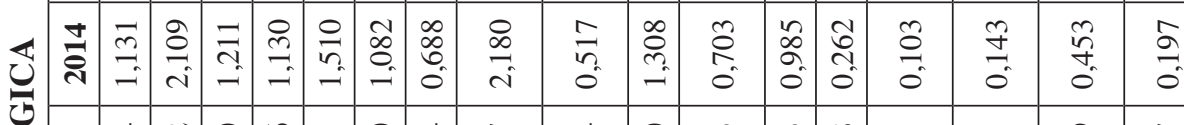

光

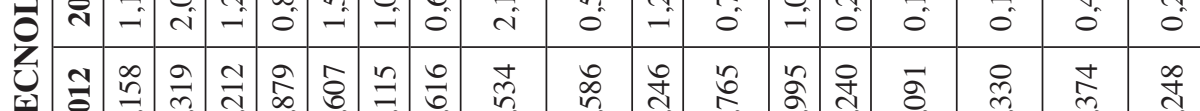

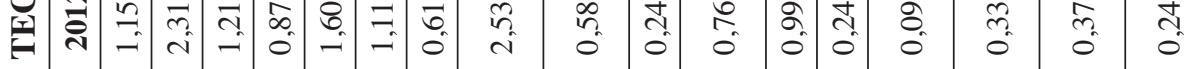

疍

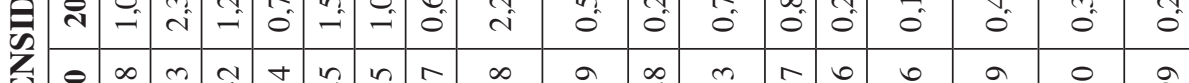

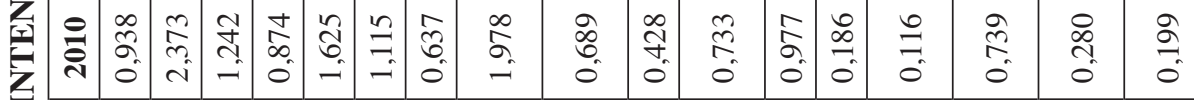

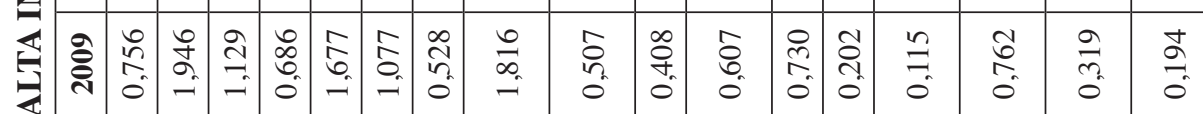

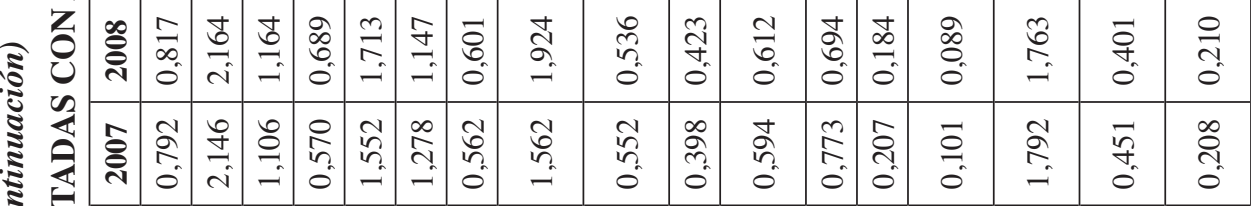

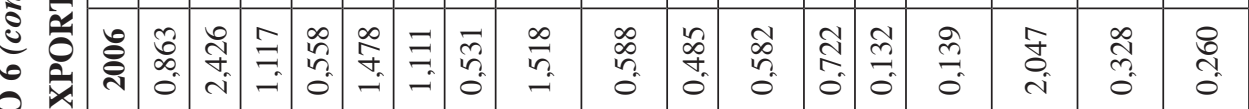

光 舟

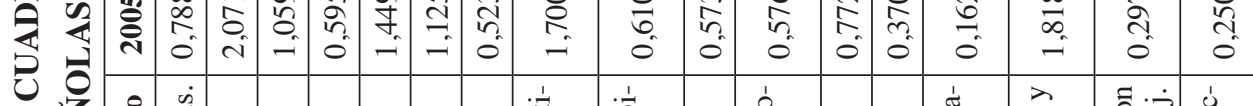

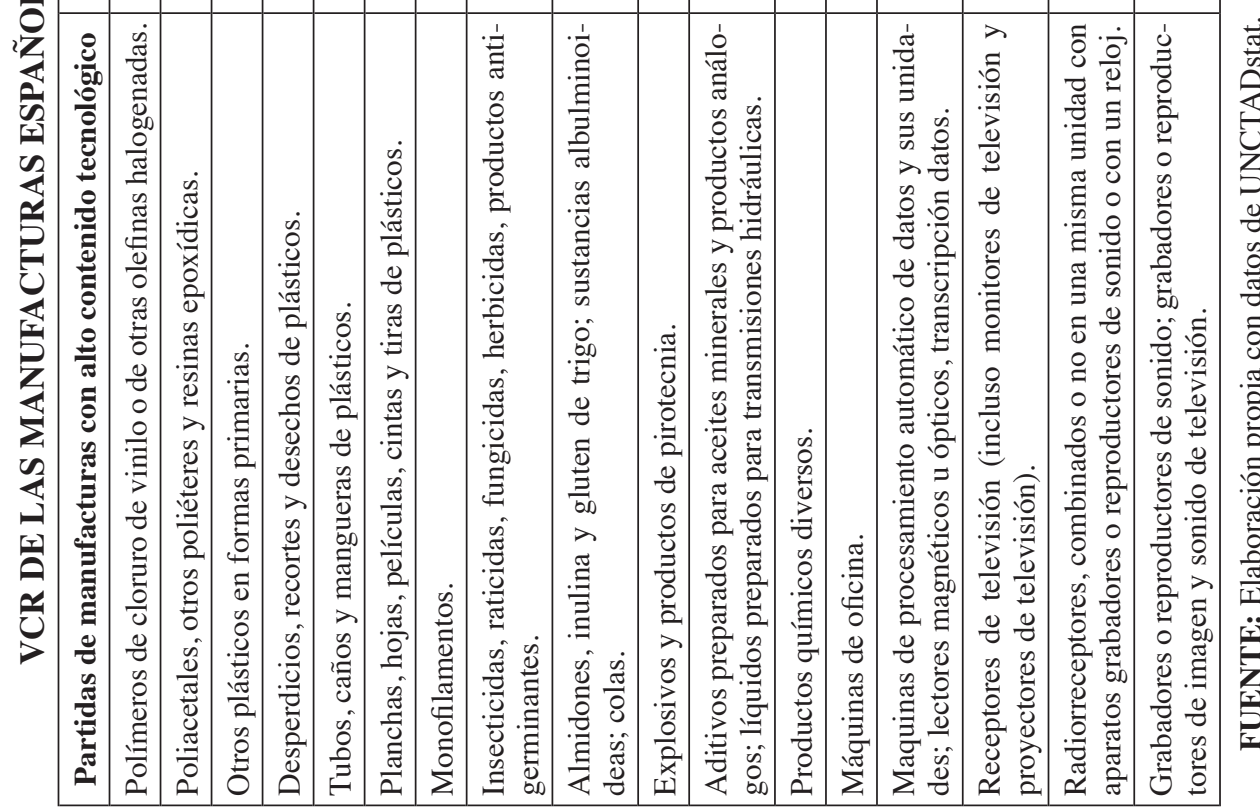




\begin{tabular}{|c|c|c|c|c|c|c|c|c|c|c|c|c|c|c|c|c|c|c|c|}
\hline & $\stackrel{n}{\bar{d}}$ & $\frac{n}{2}$ & $\begin{array}{l}\stackrel{0}{ \pm} \\
\stackrel{0}{0}\end{array}$ & $\begin{array}{l}\vec{J} \\
\dot{0} \\
0\end{array}$ & $\underset{\sim}{\stackrel{\mathbb{Z}}{-}}$ & $\begin{array}{l}\widehat{\widehat{\sigma}} \\
0 \\
0\end{array}$ & $\begin{array}{l}n \\
\stackrel{n}{*} \\
0\end{array}$ & $\begin{array}{l}\Omega \\
\varrho \\
- \\
-\end{array}$ & $\begin{array}{l}\text { O } \\
\text { Oे }\end{array}$ & $\left|\begin{array}{c}0 \\
0 \\
1 \\
2 \\
0\end{array}\right|$ & $\begin{array}{l}\hat{2} \\
\hat{2} \\
0\end{array}$ & 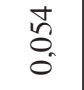 & $\begin{array}{l}\vec{n} \\
\tilde{0}\end{array}$ & $\begin{array}{l}n \\
n \\
n \\
0\end{array}$ & $\begin{array}{c}+ \\
\infty \\
\infty \\
0 \\
0\end{array}$ & त̂ & $\begin{array}{l}\overrightarrow{\tilde{N}} \\
\tilde{0}\end{array}$ & $\stackrel{\infty}{\stackrel{\infty}{d}}$ & $\hat{\hat{n}}$ \\
\hline త্ & 离 & $\begin{array}{l}\stackrel{g}{g} \\
\stackrel{-}{0}\end{array}$ & $\underset{\stackrel{P}{\Xi}}{\stackrel{\mathscr{f}}{0}}$ & \begin{tabular}{l}
\multirow{J}{+}{} \\
$\stackrel{0}{0}$ \\
0
\end{tabular} & $\stackrel{\sim}{n}$ & 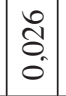 & 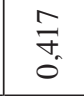 & $\begin{array}{l}\tilde{n} \\
\hat{0}\end{array}$ & $\stackrel{\text { సે }}{\stackrel{0}{0}}$ & 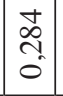 & $\begin{array}{l}\infty \\
\infty \\
2 \\
0 \\
0\end{array}$ & $\begin{array}{l}n \\
0 \\
i\end{array}$ & ڤ. & $\begin{array}{l}2 \\
\dot{2} \\
0 \\
0\end{array}$ & $\stackrel{2}{0}$ & $\begin{array}{l}\infty \\
\\
\\
-\end{array}$ & 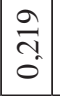 & \begin{tabular}{l}
$\exists$ \\
\multirow{2}{*}{}
\end{tabular} & กิ \\
\hline 0 & ᄅே & $\frac{\hat{N}}{0}$ & $\begin{array}{l}\vec{J} \\
\overrightarrow{0}\end{array}$ & $\begin{array}{l}0 \\
0 \\
0 \\
0\end{array}$ & $\begin{array}{l}\text { No } \\
\text { Na } \\
\text { त }\end{array}$ & $\begin{array}{l}0 \\
0 \\
0 \\
0\end{array}$ & so & $\begin{array}{l}\infty \\
\check{0} \\
0\end{array}$ & $\begin{array}{l}n \\
\infty \\
m \\
0\end{array}$ & $\left|\begin{array}{l}n \\
n \\
n \\
0\end{array}\right|$ & $\begin{array}{c}\mathbb{N} \\
\stackrel{\sigma}{\sigma} \\
0\end{array}$ & $\begin{array}{l}\text { त. } \\
\infty \\
0 \\
0\end{array}$ & $\underset{\infty}{+}$ & \begin{tabular}{c}
$\hat{F}$ \\
\multirow{\sigma}{*}{} \\
0
\end{tabular} & 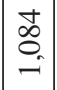 & $\begin{array}{c}\mathcal{N} \\
\underset{-}{-1} \\
-1\end{array}$ & $\begin{array}{l}n \\
n \\
0\end{array}$ & $\begin{array}{l}\overrightarrow{2} \\
\text { ?. } \\
0\end{array}$ & $\begin{array}{r}\hat{\jmath} \\
\hat{0}\end{array}$ \\
\hline 工工工 & 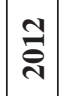 & $\frac{\mathscr{m}}{\dot{\Xi}}$ & $\underset{0}{\stackrel{a}{ \pm}}$ & $\begin{array}{l}\text { I } \\
0 \\
0 \\
0\end{array}$ & $\stackrel{n}{0}$ & $\begin{array}{l}1 \\
0 \\
0 \\
0\end{array}$ & \begin{tabular}{r}
\multirow{T}{*}{} \\
$\stackrel{\sigma}{0}$
\end{tabular} & $\begin{array}{l}\hat{\theta} \\
\infty \\
0 \\
0\end{array}$ & 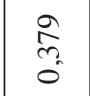 & 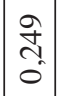 & $\begin{array}{l}\stackrel{a}{\sigma_{\alpha}} \\
\sigma_{0}\end{array}$ & $\stackrel{\infty}{\stackrel{\sim}{~}}$ & $\begin{array}{l}t \\
0 \\
0 \\
0\end{array}$ & $\begin{array}{c}m \\
\infty \\
\infty \\
0 \\
0\end{array}$ & $\mid \begin{array}{c}n \\
2 \\
0 \\
0 \\
0\end{array}$ & 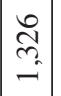 & $\begin{array}{l}n \\
\text { กิ } \\
0\end{array}$ & 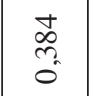 & $\frac{\sigma}{\sigma}$ \\
\hline 哥 & $\overline{\bar{ন}}$ & 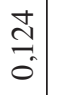 & $\frac{n}{\dddot{n}}$ & \begin{tabular}{l}
$n$ \\
\hdashline \\
0
\end{tabular} & $\stackrel{\curvearrowright}{=}$ & $\frac{\infty}{0}$ & ণ্ণ & $\begin{array}{l}\approx \\
\infty \\
=\end{array}$ & 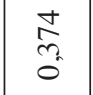 & $\left|\begin{array}{l}0 \\
n \\
2 \\
0\end{array}\right|$ & $\begin{array}{l}F \\
n \\
0\end{array}$ & $\stackrel{m}{\infty}$ & $\begin{array}{c}\mathcal{V} \\
0 \\
0 \\
0\end{array}$ & $\begin{array}{l}\stackrel{\infty}{f}_{+} \\
0^{\circ}\end{array}$ & $\begin{array}{l}\infty \\
0 \\
0 \\
0\end{array}$ & 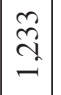 & 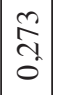 & 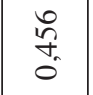 & $\frac{n}{2}$ \\
\hline 党 & 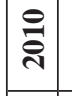 & $\stackrel{7}{ \pm}$ & $\begin{array}{l}5 \\
\Xi \\
0\end{array}$ & $\begin{array}{l}a \\
\vec{\lambda} \\
0\end{array}$ & $\begin{array}{l}n \\
\infty \\
-\end{array}$ & $\begin{array}{l}0 \\
0 \\
0\end{array}$ & $\begin{array}{l}\text { In } \\
0 \\
0\end{array}$ & $\begin{array}{l}\overrightarrow{\widehat{~}} \\
-\end{array}$ & $\begin{array}{l}n \\
\tilde{n} \\
\tilde{0}\end{array}$ & $\mid \begin{array}{l} \pm \\
2 \\
2 \\
0\end{array}$ & $\begin{array}{l}\bar{R} \\
2 \\
0\end{array}$ & $\begin{array}{l}\infty \\
\infty \\
0 \\
0\end{array}$ & $\begin{array}{c}0 \\
\infty \\
0 \\
0\end{array}$ & $\begin{array}{l}\infty \\
n \\
n \\
0 \\
0\end{array}$ & 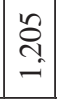 & 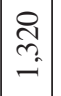 & 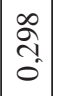 & $\begin{array}{l}\text { to } \\
\text { t. } \\
0\end{array}$ & $\underset{\text { ḋ }}{\stackrel{a}{0}}$ \\
\hline 岁 & હે్ٍతి & $\frac{2}{\sigma}$ & $\begin{array}{l}n \\
\tilde{0} \\
0\end{array}$ & $\frac{n}{n}$ & $\hat{a}$ & $\begin{array}{l}0 \\
0 \\
0 \\
0\end{array}$ & $\begin{array}{l}\text { On } \\
\stackrel{\infty}{+} \\
0\end{array}$ & \begin{tabular}{l}
8 \\
$\Xi$ \\
\hdashline \\
-
\end{tabular} & $\frac{1}{3}$ & $\begin{array}{l}m \\
\hat{\jmath} \\
0\end{array} \mid$ & $\begin{array}{l}2 \\
\infty \\
0 \\
0\end{array}$ & $\underset{-}{\stackrel{ \pm}{~}}$ & $\begin{array}{l}\tilde{N} \\
\tilde{n} \\
0\end{array}$ & $\begin{array}{l}n \\
n \\
n \\
0\end{array}$ & 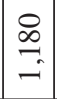 & $\begin{array}{l}0 \\
2 \\
-2\end{array}$ & 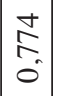 & $\begin{array}{l}\overrightarrow{0} \\
\text { n. } \\
0\end{array}$ & $\frac{0}{2}$ \\
\hline Z & 衰 & $\frac{\infty}{0}$ & $\begin{array}{l}\infty \\
\stackrel{\infty}{n} \\
0\end{array}$ & $\frac{\stackrel{ }{1}}{0}$ & 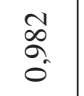 & $\overrightarrow{\widetilde{d}}$ & $\begin{array}{l}\text { ते } \\
\text { n. }\end{array}$ & $\begin{array}{c}\infty \\
\stackrel{\infty}{0} \\
-\end{array}$ & $\frac{n}{n}$ & 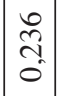 & \begin{tabular}{l}
\multirow{J}{J}{} \\
$\infty$ \\
0 \\
0
\end{tabular} & $\stackrel{\Xi}{=}$ & $\begin{array}{l}2 \\
\text { స్ } \\
0\end{array}$ & $\begin{array}{l}\bar{n} \\
n \\
0\end{array}$ & $\underset{\Xi}{\mathbb{Z}}$ & $\frac{\infty}{n}$ & 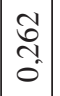 & సे. & 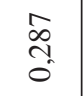 \\
\hline 2 & હิ) & $\begin{array}{l}\frac{0}{2} \\
0\end{array}$ & $\begin{array}{l}\hat{\sigma} \\
- \\
0\end{array}$ & $\begin{array}{l}2 \\
5 \\
0 \\
0\end{array}$ & $\begin{array}{l}\tilde{\sigma} \\
\hat{\sigma}\end{array}$ & 吉 & $\begin{array}{l}n \\
n \\
n \\
0\end{array}$ & $\underset{\stackrel{J}{J}}{\stackrel{\sim}{-}}$ & ๙ે. & 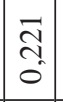 & $\stackrel{2}{\stackrel{2}{0}}$ & $\begin{array}{l}n \\
\infty \\
0\end{array}$ & $\frac{n}{2}$ & $\begin{array}{l}\bar{n} \\
2 \\
0\end{array}$ & $\begin{array}{l}\Re \\
\infty \\
=\end{array}$ & $\begin{array}{l}0 \\
2 \\
n \\
- \\
\end{array}$ & $\begin{array}{l}0 \\
\tilde{n} \\
\\
0\end{array}$ & $\frac{m}{n}$ & \begin{tabular}{l}
$\infty$ \\
$\infty$ \\
\multirow{1}{0}{} \\
0
\end{tabular} \\
\hline $\begin{array}{l}0 \\
8\end{array}$ & ఏ్తి & $\begin{array}{l}\text { ָิ } \\
\text { ָ̇ } \\
0\end{array}$ & $\begin{array}{l}\vec{J} \\
\overrightarrow{0}\end{array}$ & 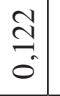 & $\begin{array}{l}\infty \\
\infty \\
\infty \\
0\end{array}$ & है. & $\begin{array}{l}\infty \\
\infty \\
2 \\
0\end{array}$ & $\begin{array}{c}\infty \\
\stackrel{\sim}{\sim} \\
\stackrel{\sim}{-}\end{array}$ & 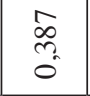 & $\stackrel{3}{I}$ & $\begin{array}{l}\stackrel{n}{\circ} \\
0 \\
0\end{array}$ & $\begin{array}{l}\vec{m} \\
\text { m. } \\
0\end{array}$ & $\begin{array}{l}0 \\
0 \\
0 \\
0\end{array} \mid$ & $\begin{array}{l} \pm \\
n \\
n \\
0\end{array}$ & $\begin{array}{l}\stackrel{0}{\alpha} \\
\hat{0}\end{array}$ & $\stackrel{\infty}{\underset{N}{\sim}}$ & 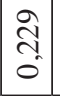 & $\begin{array}{l}\text { oे } \\
\text { +े }\end{array}$ & ๙ิ \\
\hline$\stackrel{2}{3}$ & ๕్ & 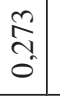 & $\begin{array}{l}\stackrel{0}{n} \\
\stackrel{0}{0}\end{array}$ & $\stackrel{\infty}{\infty}$ & $\underset{\infty}{\leftrightarrows}$ & $\vec{F}$ & 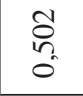 & 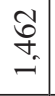 & 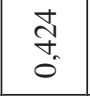 & 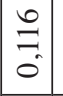 & \begin{tabular}{l}
$\infty$ \\
\multirow{0}{0}{} \\
0
\end{tabular} & $\stackrel{\infty}{\stackrel{0}{0}}$ & 点 & 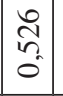 & $\begin{array}{l}0 \\
\sigma \\
0\end{array}$ & $\begin{array}{l}2 \\
\approx \\
-\end{array}$ & 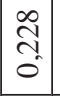 & $\begin{array}{l}\text { \&े } \\
\text { †े } \\
0\end{array}$ & $\begin{array}{l}\mathbb{J} \\
\text { ?. } \\
0\end{array}$ \\
\hline 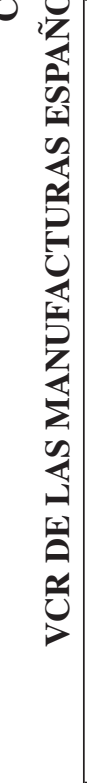 & 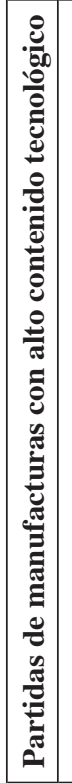 & 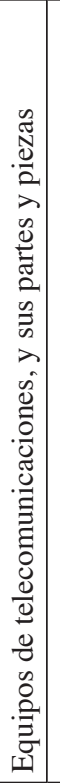 & 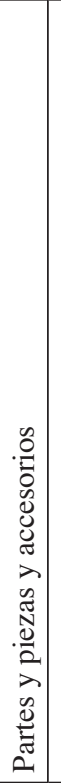 & 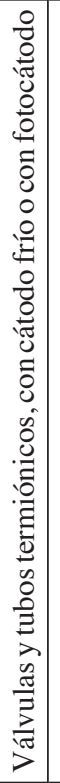 & 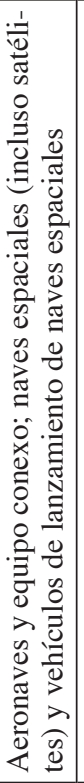 & 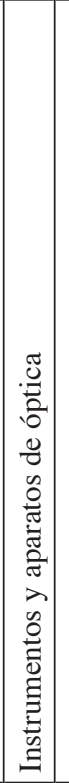 & 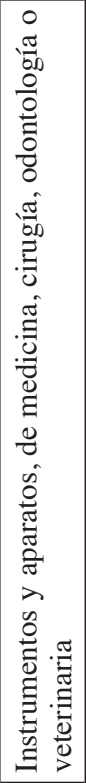 & 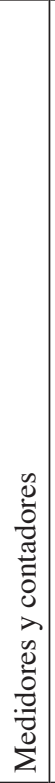 & 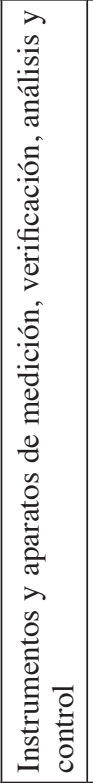 & 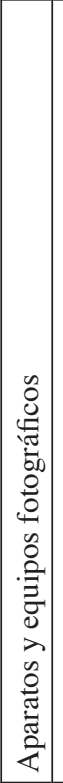 & 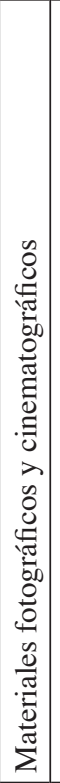 & 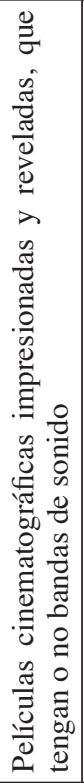 & 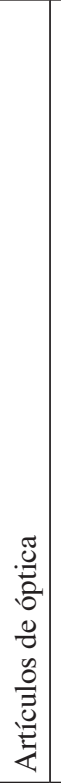 & $\mid \begin{array}{c}\frac{\tilde{0}}{0} \\
\frac{0}{\tilde{v}} \\
\tilde{q}\end{array}$ & 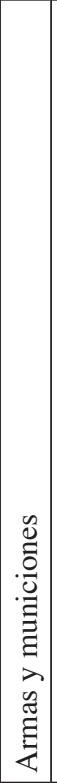 & 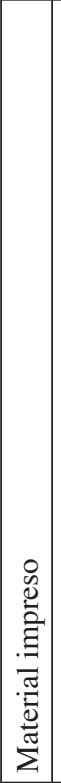 & 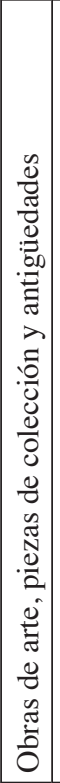 & 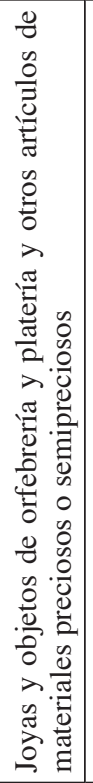 & 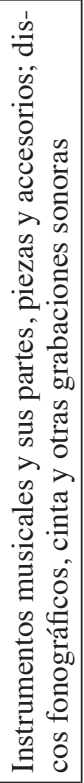 \\
\hline
\end{tabular}




\section{Conclusiones}

Este trabajo ha examinado las exportaciones de manufacturas españolas a la ASEAN atendiendo a su intensidad tecnológica, realizando una comparativa con los nueve países de la UE que exportaron en promedio un mayor valor de manufacturas, y con algunos de los principales países exportadores mundiales de manufacturas a la ASEAN, durante el periodo comprendido entre el año 2005 y el año 2015, y prestando una especial atención a las manufacturas con un mayor contenido tecnológico.

A lo largo del trabajo se han observado posibles potencialidades para las exportaciones españolas de manufacturas a la ASEAN. Se ha puesto de manifiesto que la Gran Recesión supuso un descenso importante de las exportaciones españolas de manufacturas, pero que aquellas con destino a la ASEAN con alto contenido tecnológico experimentaron una mayor resiliencia.

En su afán de incrementar las exportaciones de bienes, tanto cuantitativa como cualitativamente, las autoridades españolas han puesto en marcha en los últimos años iniciativas tales como la «Agenda para el Fortalecimiento del Sector Industrial en España», o la «Estrategia de Internacionalización de la Economía Española», en las que entre otros objetivos se establecen: la mejora de la composición tecnológica de las manufacturas españolas exportadas, y la necesidad de abordar nuevos mercados.

El presente trabajo ahonda en estos dos objetivos, concretando las oportunidades que la ASEAN ofrece a las empresas españolas, especialmente en los segmentos de manufacturas con mayor contenido tecnológico. Para ello se detallan las manufacturas que más importan, identificando a través de unos índices generalmente aceptados la complementariedad de los patrones de exportaciones e importaciones, el grado de concentración de las exportaciones, y las VCR de las principales manufacturas españolas exportadas.

A priori, y siendo conscientes de la necesidad de completar el análisis de la complementariedad del comercio con otras variables, los índices de complementariedad revelan que un mayor grado de integración entre la UE y la ASEAN podría ser beneficioso para las exportaciones españolas de manufacturas con alto contenido tecnológico.

Asimismo, y teniendo igualmente en cuenta las limitaciones del índice de concentración, se ha observado que un alto grado de concentración de las exportaciones de manufacturas a la ASEAN, no supone una ventaja a la hora de mejorar cuantitativamente las exportaciones de manufacturas con alta intensidad tecnológica. Al analizar las VCR que presentan las manufacturas españolas exportadas a la ASEAN, se observa que esas ventajas no son relevantes entre las manufacturas de alta intensidad tecnológica más importadas por la ASEAN, y también se observa que de las veintiuna manufacturas españolas con alta intensidad tecnológica que presentan VCR, pocas están entre las más exportadas por España a la ASEAN. Toda esta información nos lleva a recomendar la posibilidad de introducir nuevos criterios en el diseño y 
evaluación de las políticas económicas encaminadas a maximizar las exportaciones españolas de manufacturas con alto contenido tecnológico.

\section{Referencias bibliográficas}

[1] AW, B. Y.; ROBERTS, M. J. y XU, D. Y. (2011). «R\&D investments, exporting and productivity dynamics». American Economic Review, 101 (4), 1312-44.

[2] BALASSA, B. (1965). «Trade Liberalisation and 'Revealed' Comparative Advantage». The Manchester School, 33, 99-123.

[3] CARRERE, C.; CADOT, O. y STRAUSS-KAHN, V. (2011). «Export Diversification: What's behind the Hump?». Review of Economics and Statistics, 93 (2), 590-605.

[4] CHEN, J.; SOUSA, C. M. P. y XINMING, H. (2016). «The determinants of export performance: a review of the literature 2006-2014». International Marketing Review, 33 (5), 626-670.

[5] FUGAZZA, M. (2004). «Export performance and its Determinants; Supply and Demand Constraints». UNCTAD Policy Issues in International Trade and Commodities Study Series, 26.

[6] GROSSMAN, M. G. y HELPMAN, E. (2003). «Outsorcing Versus FDI in Industry Equilibrium». Journal of the European Economic Association, April-May 2003, 317 327.

[7] GROSSMAN, G. y ROSSI-HANSBERG, E. (2006). The Rise of offshoring: it's not wine for cloth anymore. Princeton University and Federal Reserve Bank of Kansas City, 59-102.

[8] HAUSMANN, R.; HWANG, J. y RORIK, D. (2007). What you export matters. Journal of Economic Growth, 12 (1), 1-25.

[9] HELPER, S.; KRUEGER, T. y WIAL, H. (2012). Why does manufacturing matter? Which manufacturing matters? A policy framework. Brookings Metropolitan Policy Program.

[10] HERFINDAHL, O. (1950). Concentration in the U.S. Steel Industry. Unpublished Dissertion. Columbia University. New York.

[11] HIRSCHMAN, A. O. (1945). National Power and the Structure of Foreign Trade. University of California Press: Berkeley, CA.

[12] KLOTZ, S.; KNIAHIN, D. y JANSEN, M. (2016). «ITC assessment of the technology level of exports: methodology and analytical issues». International Trade Center Working Papers Series, WP-01-2016.E.

[13] LALL, S. (2000). «The technological structure and performance of developing countries manufactured exports, 1985-1998», Queen Elizabeth House Working Papers, 44.

[14] MERINO, F. y RODRÍGUEZ, D. (2007). «Business services outsourcing by manufacturing firms». Industrial and Corporate Change, 16 (6), 1147-1173.

[15] MICHAELY, M. (1996). «Trade Preferential Agreements in Latin America: An Ex-Ante Assessment». World Bank Policy Research Working Paper, 1583.

[16] NACIONES UNIDAS, DEPARTAMENTO DE ASUNTOS SOCIALES Y ECONÓMICOS, DIVISIÓN DE ESTADÍSTICA (2008). Internacional Standard Industrial Classification for all Economic Activities Rev., 4, 
[17] OCDE. (2017). Economic Outlook for Southeast Asia, China and India.

[18] ORGANIZACIÓN MUNDIAL DEL COMERCIO (2012). A Practical Guide to Trade Policy Analysis.

[19] YOFFIE, D. B. y HAZARD, H. A. (1989). «New Theories of International Trade». HBS Case Colletion Harvard Business School. 